\title{
Cationic Starch-based Hydrogel Synthesized by Gamma Irradiation
}

\author{
Hongjuan Zheng*, Weiqiang Song, Yanrong Wang, Yantao Li \\ School of Materials Science and Engineering, Henan University of Technology, Zhengzhou 450001, \\ China \\ *Corresponding author. e-mail address: zhj6287@163.com (Hongjuan Zheng).
}

Keywords: gamma irradiation; starch; allyl triphenyl phosphonium bromide

\begin{abstract}
Cationic starch-based hydrogel was synthesized by simultaneous gamma irradiation of starch (St), acrylamide (AAM), allyl triphenyl phosphonium bromide (APB) and N,N'-methylene bisacrylamide (MBA) as cross-linker in aqueous solution. The molecular mass of the un-grafted AAM/APB copolymer, the cationic degree and the glass temperature $\left(T_{g}\right)$ of the resulting starch-based hydrogel increase with absorbed dose increasing, but no obvious change of thermal stability is observed. Moreover, the swelling equilibrium ratio $\left(S_{e}\right)$ of the dry hydrogel decreases with absorbed dose increasing. Gel fraction continually increases with increasing AAM/APB mass ratio, but decreases by increasing starch/(AAM+APB) mass ratio at a fixed absorbed dose of $3 \mathrm{kGy}$. $\mathrm{S}_{\mathrm{e}}$ decreases initially and then increased with increasing AAM/APB mass ratio.
\end{abstract}

\section{Introduction}

Wastewater generating from different sources such as electroplating, surface finishing, paper making etc, contains heavy metals with environmental hazards. The treatment of such wastewater for the removal of heavy metal is much concerned in environmental engineering and policy. Commercial anion-exchanging resins containing tertiary amine and quaternary ammonium groups are very effective in industrial wastewater treatment to remove heavy metal anions. But these anion-exchanging resins are petrochemically based, the industrial application of this antipollution technique has been limited because of the present petrochemical shortages. This problem has been solved by using a naturally occurring, annually renewable, low-cost polymer such as starch. But starch cannot be used directly due to its intrinsic properties. Modified starches are supposed to overcome the inherent drawbacks and to ease its applications.

Starch can be highly cross-linked by chemical cross-linking technology and gamma irradiation, and chemical modification with various reactive cationic monomers imparts cationic properties to starch. Cationic starch after cross-linking becomes insoluble in water, so it can be used for removal of heavy metal ion. Generally, cationic starches are derived from parent starches modified either with etherifying agents containing active nitrogen or with cationic radical-polymerizable monomers essentially based on ammonium, phosphonium, or imidazolium cations [1]. Ammonium-based starches are most cited among cationic flocculants and adsorbents, while quaternary phosphonium based cross-linked starch is rare in literatures. Compared to similar ammonium analogs,phosphonium salts are particularly attractive due to greater thermal stability and antimicrobial activity [2,3], which is due to the weaker electronegativity and bigger size of phosphorus compared to nitrogen.

Grafting of a radical-polymerizable phosphonium salt-containing monomer onto starch backbone can be initiated either by gamma irradiation or by a radical initiator [4]. Gamma irradiation is a technique characterized by mild variation of temperature and no catalysts dependence, which provides a low-cost and environment-friendly alternative to alter the physical, chemical, and/or biological characteristics of a product [5-11]. When polymeric materials are exposed to gamma

radiation, they either undergo degradation (chain scission) or cross-linking (chains covalently linked). The degradation and the cross-linking are two competing processes during irradiation. The overall effect depends on which of the two is predominant at a certain time [12]. Polysaccharides and their derivatives exposed to gamma radiation had been long recognized as a degradable type of 
polymers. Gamma irradiation of polysaccharides leads to breakdown of the ordered system of intermolecular as well as intramolecular hydrogen bonds. Consequently, the rigidity of chains is influenced by intramolecular hydrogen bonding, and therefore the degree of crystallinity of the material decreases. Polysaccharides irradiated in solid state and in diluted aqueous solutions suffer scission of acetal linkages in main chains. Random cleavage of glycoside bonds in the main chain, initialized by radicals on macromolecules was found to be a leading reaction [13]. Otherwise, at high concentration, gamma irradiation had been reported to lead to cross-linking of starches, and therefore these starches formed hydrogels. As a useful method for producing modified starches, gamma irradiation generates free radicals on starch backbones that alter molecular size and structures. Several studies on the effects of gamma radiation on wheat starch, barley endosperm, and corn starch had been conducted [13-17].

Cationic starch graft polymers comprising acrylamide can be further cross-linked if cross-linking agents having a functionality of two were used during the graft polymerization of acrylamide and a cationic vinyl monomer [18]. In the present work, cationic cross-linked copolymers of starch (ST), acrylamide (AAM), allyl triphenyl phosphonium bromide (APB), and N,N'-methylene bisacrylamide (MBA) as cross-linker, were prepared using gamma irradiation as initiator, and the resulted cross-linked ST/AAM/APB/MBA gels were characterized. The effects of absorbed dose and monomer concentration on the gel fraction, cationic degree and swelling behavior of dry hydrogels were investigated.

\section{Materials and methods}

\section{Materials}

Food grade corn starch (ST) powder was supplied from Henan Yongchang Starch Sugar Co., Ltd.. Allyl triphenyl phosphonium bromide (APB, analytical grade) was purchased by A Johnson Matthey Company. Acrylamide (AAM, analytical grade) was obtained from Tianjin NO.3 Chemical Reagent Factory. All other chemicals were analytical grade. Double distilled water was used for preparation and measurements.

\section{Gamma irradiation}

Corn starch powder was first dissolved in distilled water to form gel-like solution and then mixed with AAM, APB and MBA wherein the amount of the binary monomers was 70 times of that of MBA. The mixture was continuously stirred under nitrogen atmosphere until a homogeneous dispersion was obtained. Thereafter, the homogeneous mixture was transferred into a wide-mouth, screw-cap glass bottle and purged with nitrogen. The bottle was tightly closed with a cap, irradiated with cobalt 60 at room temperature at an average irradiation dose rate of $40 \mathrm{~Gy} / \mathrm{min}$, and allowed to stand at ambient temperature for $2 \mathrm{hr}$. The gelatinous products of St/AAM/APB/MBA were obtained after irradiation.

\section{Gel fraction}

The gelatinous sample was crushed, vacuum-dried at $60^{\circ} \mathrm{C}$ and ground into fine powder. The powder was extracted continuously for 18 hours in a Soxhlet extractor with a mixture of acetone and glacial acetic acid $(1: 1 \mathrm{v} / \mathrm{v})$, and then dried in a vacuum oven at $60^{\circ} \mathrm{C}$ to a constant mass. Gel fraction $\left(G_{f}\right)$ was measured gravimetrically [16].

$$
G_{f}=m_{0} / m \times 100
$$

Where $m_{0}$ is the mass of the dry gel after extraction and $m$ is the initial mass of dry gel.

\section{NMR study}

Proton nuclear magnetic resonance (NMR) spectra were recorded in deuterium oxide $\left(\mathrm{D}_{2} \mathrm{O}\right)$ on a Bruker Avance $300 \mathrm{MHz}$, Germany. Chemical shifts were recorded as values in parts per million (ppm) and referenced to the solvent used (i.e. $\mathrm{D}_{2} \mathrm{O}$ ).

\section{Gel permeation chromatography}

Gel permeation chromatography (GPC) was performed with a Shimadzu LC-10Avp HPLC fitted with a Shodex Asahipak GF-310 HQ column and a differential refractive index detector in distilled water as eluent. 


\section{Thermal analysis}

A Netzsch DSC 200F3 instrument was used to measure thermal transitions and degree of crystallinity of the samples. Specimens of 5-12 mg were encapsulated in aluminum pans and non-isothermal experiments were performed in the temperature range from $20{ }^{\circ} \mathrm{C}$ to $250{ }^{\circ} \mathrm{C}$ at a heating rate of $10^{\circ} \mathrm{C} / \mathrm{min}$.

A Netzsch STA 409 PC/PG instrument was used for the thermo-gravimetric analysis (TGA). The instrument was calibrated both for temperature and mass by the usual methods. Non-isothermal experiments were performed in the temperature range from $30^{\circ} \mathrm{C}$ to $600{ }^{\circ} \mathrm{C}$ at a heating rate of $10{ }^{\circ} \mathrm{C}$ $/ \mathrm{min}$. The average sample size was $4 \mathrm{mg}$ and the dry nitrogen flow rate was $30 \mathrm{ml} / \mathrm{min}$.

\section{Determination of swelling behavior}

In order to determine the swelling behavior of ST/AAM/APB/MBA hydrogels, initially dry gels were immersed in distilled water and kept at room temperature. At consecutive time intervals, swollen gels were removed from the water bath and quickly blotted with filter paper for removal of excess water on the surface of the sample. And then swollen gels were weighed by means of an electronic balance and re-immersed in the same bath. The measurement was continued until a constant mass was achieved for each sample. The equilibrium degree of swelling of ST/AAM/APB/MBA gel $\left(S_{e}\right)$ was calculated by the following equation:

$$
S_{e}=\frac{m_{e}-m_{0}}{m_{0}} \times 100 \%
$$

Where $m_{e}$ is the mass of gel at the equilibrium and $m_{0}$ is the mass of the dry gel.

\section{Determination of cationic degree}

Cationic degree $(C D)$ of ST/AAM/APB/MBA gels was determined by titration (Mohr's method) [19], which depended upon the amount of APB unit incorporated into the gel. $C D$ used in $\mathrm{m} \mathrm{mol} / \mathrm{g}$ is calculated by Eq.(3).

$$
C D=\frac{M \times\left(V-V^{0}\right)}{m}
$$

Where, $M$ is the molarity of $\mathrm{AgNO}_{3}$ used in $\mathrm{m} \mathrm{mol} / \mathrm{ml}, V$ is the volume of the silver nitrate standard solution consumed during titration used in $\mathrm{ml}, V^{0}$ is the volume of the silver nitrate standard solution consumed during blank titration used in $\mathrm{ml}$.

\section{Results and Discussion}

\section{Synthesis and Mechanistic Aspect}

When an aqueous solution of St/AAM/APB was exposed to gamma radiation, free radicals were generated not only by reaction with starch and monomers, but even more efficiently with the solvent, i.e. water. Water absorbed radiant energy, and then $\cdot \mathrm{OH}, \cdot \mathrm{H}, \mathrm{e}_{\mathrm{aq}}^{-}, \mathrm{H}_{2} \mathrm{O}_{2}, \mathrm{H}_{2}$ and $\mathrm{H}^{+}$might be generated as the result of the water radiolysis. Water radiolysis can be written as [20]:

$$
\mathrm{H}_{2} \mathrm{O} \stackrel{\text { lonizing Radiation }}{\longrightarrow} \mathrm{e}_{\mathrm{aq}}^{-}, \cdot \mathrm{OH}, \cdot \mathrm{H}, \mathrm{HO}_{2}, \mathrm{H}_{3} \mathrm{O}^{+}, \mathrm{OH}^{-}, \mathrm{H}_{2} \mathrm{O}_{2}, \mathrm{H}_{2}
$$

Subsequently, $\cdot \mathrm{OH}, \cdot \mathrm{H}, \mathrm{e}_{\mathrm{aq}}^{-}, \mathrm{H}_{2} \mathrm{O}_{2}$ and $\mathrm{H}^{+}$initiated homo-polymerization and copolymerization of AAM and APB, which resulted in polyAAM, polyAPB and AAM/APB copolymers. $\cdot \mathrm{OH}$ was very efficient in initiating polymerization of $\mathrm{AAM}$ and $\mathrm{APB}$, and more effective than other radicals in attacking polymer chains by abstracting carbon-bound $\mathrm{H}$-atoms from starch backbones and AAM/APB copolymer chains, and as a result, macro-radicals were simultaneously formed. In addition, starch and AAM/APB copolymer directly absorbed radiation energy and generated macro-radicals [21-24]. When two macro-radicals combined, a cross-link was formed. The growth of AAM and APB on the activated macro-radicals leaded to branching and further to cross-linking at the presence of a bi-functional monomer, i.e., MBA. 


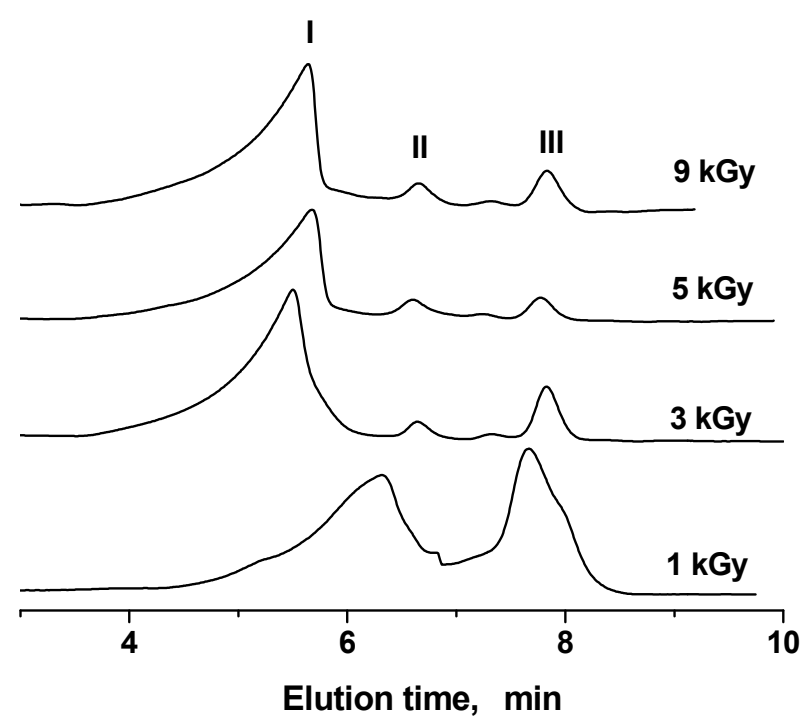

Fig. 1. GPC chromatograms for the portion dissolving into the solution in products synthesized at 1, 3, 5 and $9 \mathrm{kGy}$ with a constant $\mathrm{St} / \mathrm{AAM} / \mathrm{APB}$ mass ratio of $6: 8.4: 5.6$

Table 1. Parameters for chromatographic elution peak I and II

\begin{tabular}{|l|l|l|l|l|l|l|}
\hline $\begin{array}{l}\text { Absorbed } \\
\text { dose, kGy }\end{array}$ & \multicolumn{3}{|c|}{$\begin{array}{c}\text { Peak I } \\
M_{\mathrm{w}} \times 10^{-4} M_{\mathrm{n}} \times 10^{-4} D\end{array}$} & \multicolumn{3}{c|}{ Peak II } \\
\hline 1 & 0.290 & 0.087 & 3.33 & & & \\
\hline 3 & 16.1 & 7.03 & 2.29 & 378 & 244 & 0.645 \\
\hline 5 & 6.78 & 2.87 & 2.36 & 451 & 353 & 1.28 \\
\hline 9 & 7.3 & 3.39 & 2.15 & 367 & 369 & 0.995 \\
\hline
\end{tabular}

After exposure to gamma radiation and followed by vacuum drying, the resulting product was extracted with a mixture of acetone and glacial acetic acid $(1: 1 \mathrm{v} / \mathrm{v})$. A portion of the resulted product dissolving into the solution phase was observed and then confirmed by GPC technique, as shown in Fig. 1. The GPC curve exhibited multiple peaks. Theoretically, peak I at low elution time corresponded to a high-molecular-weight fraction, while peak II and III at high elution times corresponded to low-molecular-weight fractions. Parameters relating to elution peak I and II are listed in Table 1. The fraction corresponding to peak III might possessed so low molecular weight that its molecular weight was beyond the inferior limit of a calculation method. Peak I exhibited higher molecular weight at $3 \mathrm{kGy}$, and moderate molecular weight at 5 and $9 \mathrm{kGy}$, while lower molecular weight and a broader distribution at $1 \mathrm{kGy}$. In addition, the content corresponding to peak III at $1 \mathrm{kGy}$ was much high in the dissolving portion.

Generally, gamma irradiation might caused both scission and cross-linking of starch, which always co-existed under radiation. The overall effect depended on which of the two was predominant at a certain time [12]. Starch irradiated in solid state and in diluted aqueous solutions suffered scission of acetal linkages in main chains. Random cleavage of glycoside bonds in the main chain, initialized by radicals placed on macromolecules, was found to be a leading reaction [13]. Otherwise, at high concentration, gamma irradiation had been reported to lead to cross-linking of starch and form hydrogel [13-16]. Irrespective of radiation cross-linking, gamma irradiation caused scission in the glycosidic chains randomly. Therefore, scissions of the chains probably produced short amylose chains and short linear chains from the branches of amylopectin or small-branched fraction of the amylopectin [25]. Reasonably, peak II was due to some fractions getting detached by the cross-linking process (e.g., chain scission during radiation).

On the other hand, gamma irradiation was usually used to prepare AAM hydrogel. When AAM and APB monomers in aqueous phase were irradiated with gamma ray, copolymerization of the monomers was initiated and PAAM/APB was achieved [26, 27]. So, peak I was due to PAAM/APB which was not incorporated into ST/AAM/APB network. On the other hand, APB monomer was not easy to polymerize because of the electrostatic repulsion. Reasonably, peak III was due to APB 
monomer. And the content of un-polymerized APB monomer decreased by increasing absorbed dose as shown in Figure 1.

To confirm that the resulted product comprised APB, proton $\left({ }^{1} \mathrm{H}\right)$ nuclear magnetic resonance $\left({ }^{1} \mathrm{H}\right.$ NMR) spectrum of the ST/AAM/APB copolymer was recorded in deuterium $\left(\mathrm{D}_{2} \mathrm{O}\right)$. Although ${ }^{1} \mathrm{H}$ NMR spectrum was complicated, the chemical shifts in $7.726,7.637$ and $7.574 \mathrm{ppm}$ proved the presence of APB moieties in the copolymer [28].

\section{Effect of absorbed dose on ST/AAM/APB/MBA hydrogel}

Swelling behavior is significant characteristic of a gel. In order to investigate the effect of absorbed dose on the swelling behavior of ST/AAM/APB hydrogel, the hydrogel was synthesized by using gamma radiation and absorbed dose was increased from 1 to $9 \mathrm{kGy}$ at a fixed 6:8.4:5.6 mass ratio of ST/AAM/APB wherein the content of AAM/APB binary monomers was 70 times of that of MBA. And, $S_{e}, C D$ and $G_{f}$ of the hydrogel as functions of absorbed dose were shown in Figure 2. A linearly decreasing trend was observed for $S_{e}$, while an opposite one was observed for $C D$ by increasing absorbed dose.

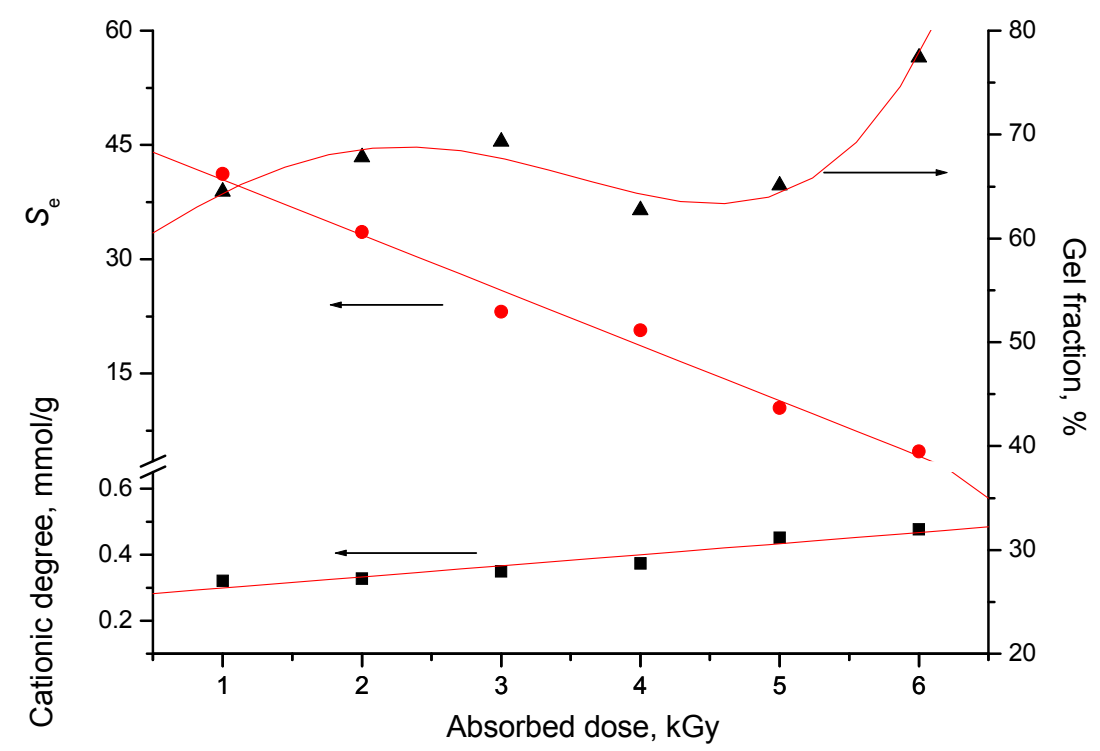

Fig. 2. $\mathrm{S}_{\mathrm{e}}$, cationic degree and gel fraction of ST/AAM/APB xerogels prepared by gamma irradiation

As known, a hydrogel had a capacity to hold water within its porous structure. The water holding capacity of the hydrogel arised mainly due to the presence of hydrophilic groups, Viz. amine, carboxyl, hydroxyl and ionic groups, in the polymer chains, which was dependent on the number of the hydrophilic groups and cross-linking density. Higher the number of the hydrophilic groups, higher was the water holding capacity while there was a decrease in the equilibrium swelling with an increase in the cross-linking density $[29,30]$.

ST/AAM/APB hydrogel was ionized as known, and therefore its swelling behavior depended on both the degree of cross-linking of the gel and electrostatic repulsion among the cationic phosphonium groups in the gel. The decrease in $S_{e}$ indicated the increase in degree of cross-linking with the increase in absorbed dose, although the electrostatic repulsion increased with the increase in cationic degree resulted from the increase in absorbed dose. In contrast with $\mathrm{S}_{\mathrm{e}}$ and cationic degree, gel fraction of the sample irradiated at dose of $4 \mathrm{kGy}$ was minimum. 


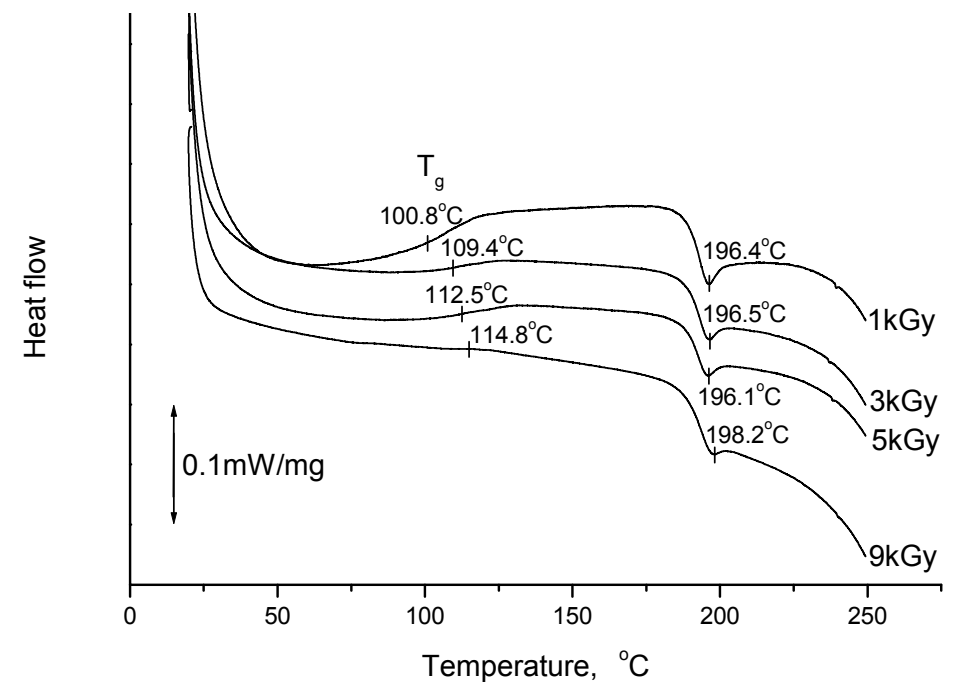

Fig. 3 DSC thermograms of the 2nd heating scan of ST/AAM/APB xerogels prepared by gamma irradiation.

The DSC thermograms for the 2nd heating scan of 1, 3, 5 and $9 \mathrm{kGy}$ ST/AAM/APB hydrogels were shown in Figure 3. For 1, 3, 5 and $9 \mathrm{kGy}$ samples, a single relatively sharp melting peak was observed at $196.4{ }^{\circ} \mathrm{C}, 196.5^{\circ} \mathrm{C}, 196.1{ }^{\circ} \mathrm{C}$ and $198.2^{\circ} \mathrm{C}$, respectively in Figure 3, which indicated that the crystallinity of the samples arised from crystallinity of the AAM/APB graft chain. Moreover, for all investigated samples, their melting temperature range was limited in $187.3-203.5{ }^{\circ} \mathrm{C}$. The corresponding heat of fusion was $1.587 \mathrm{~J} / \mathrm{g}, 1.229 \mathrm{~J} / \mathrm{g}$ and $0.5928 \mathrm{~J} / \mathrm{g}$ for 1,3 , and $5 \mathrm{kGy}$ samples, respectively, which indicated that the crystallinity of ST/AAM/APB xerogels decreased with increasing absorbed dose, while the heat of fusion for $9 \mathrm{kGy}$ sample was $0.6412 \mathrm{~J} / \mathrm{g}$.

For 1, 3 and $5 \mathrm{kGy}$ samples, glass transitions could be clearly observed, but a weak glass transition was observed for $9 \mathrm{kGy}$ sample, and the glass temperature $(\mathrm{Tg})$ was $100.8{ }^{\circ} \mathrm{C}, 109.4{ }^{\circ} \mathrm{C}$, $112.5{ }^{\circ} \mathrm{C}$ and $114.8{ }^{\circ} \mathrm{C}$, respectively in Figure 3, which indicated that the glass transition was suppressed by cross-linking structure in samples rendered by gamma irradiation.

The thermal stability of ST/AAM/APB xerogels after extracting was shown by the TGA data in Figure 4, respectively. All of ST/AAM/APB xerogels showed three distinct degradation steps. The small mass loss prior to the primary degradation process was believed to be due to water evolution. The ST/AAM/APB xerogels were thermally stable to $\sim 270{ }^{\circ} \mathrm{C}$, and the continuous mass loss from 270 to $550{ }^{\circ} \mathrm{C}$ could be observed, and their primary degradation temperature slightly varied from one to another. The first primary degradation temperature is $275.5^{\circ} \mathrm{C}, 277.6{ }^{\circ} \mathrm{C}, 273.6{ }^{\circ} \mathrm{C}$ and $276.1{ }^{\circ} \mathrm{C}$ for $1,3,5$ and $9 \mathrm{kGy} \mathrm{ST} / \mathrm{AAM} / \mathrm{APB}$ xerogels, respectively, which was due to degradation of AAM/APB graft chain. The second primary degradation occurs at $290.4{ }^{\circ} \mathrm{C}, 291.8{ }^{\circ} \mathrm{C}, 291.7{ }^{\circ} \mathrm{C}$ and $293.7{ }^{\circ} \mathrm{C}$ for these xerogels, respectively, which was attributed to the decomposition of starch composition.

\section{Effect of APB concentration on the swelling behavior of ST/AAM/APB hydrogels}

In order to investigate the effect of APB concentration on the swelling behavior of ST/AAM/APB hydrogels, several samples were synthesized in $60 \mathrm{ml}$ distilled water at a fixed absorbed dose of 3 $\mathrm{kGy}$ with AAM/APB mass ratio varying in the range of 0:14 to 11.2:2.8 and simultaneously with a fixed $6: 14 \mathrm{~g} / \mathrm{g}$ ratio of starch/binary monomers. $\mathrm{S}_{\mathrm{e}}$ and cationic degree as functions of AAM/APB mass ratio were shown in Figure 5. $\mathrm{S}_{\mathrm{e}}$ decreased initially with increasing AAM/APB mass ratio up to 8.4:5.6 and then increased. On the contrary, cationic degree increased initially with increasing AAM/APB mass ratio up to 8.4:5.6 and then decreased. Gel fraction continually increased with increasing AAM/APB mass ratio, whereas it exhibited a progressive decrease.

The effect of the concentration of the binary monomers on the swelling of ST/AAM/APB hydrogels was investigated further. Six samples were synthesized in $60 \mathrm{ml}$ distilled water at a fixed absorbed dose of $3 \mathrm{kGy}$ with the ratio of starch/binary monomers increasing from $6: 3$ to $6: 18$ and simultaneously with a fixed 8.4:5.6 mass ratio of $A A M / A P B$, and $S_{e}$ and cationic degree as functions 
of the ration between starch and binary monomers were shown in Figure 6 . $\mathrm{S}_{\mathrm{e}}$ initially decreased and then tended to be constant, but cationic degree increased and then tended to be constant, along with increasing starch/binary monomers mass ratio.

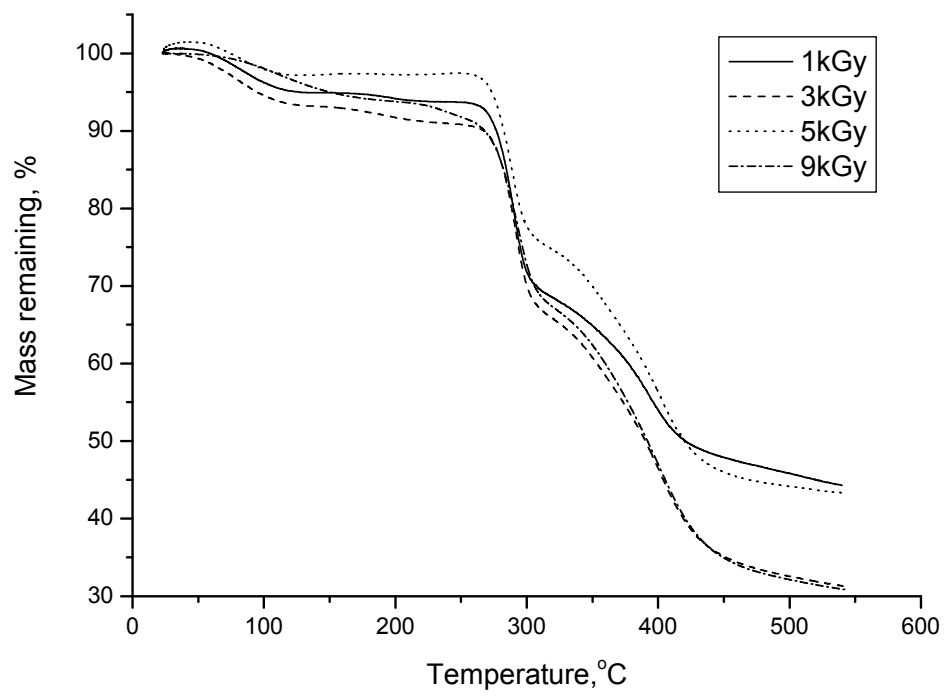

Fig. 4. TGA thermograms of ST/AAM/APB xerogels prepared by gamma irradiation

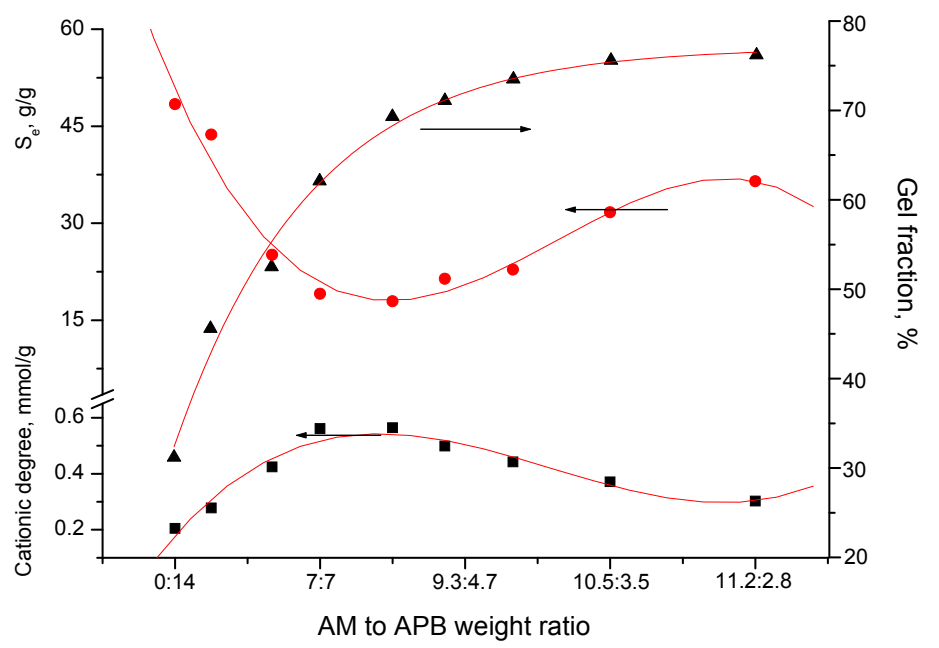

Fig. 5. Effect of AAM/APB mass ratio on $S_{\text {e }}$, cationic degree and gel fraction of ST/AAM/APB

The effect of starch/(AAM+APB) mass ratio was similar to that of absorbed dose on gel fraction of ST/AAM/APB hydrogels (as shown in Fig. 2), but was distinguished from that of AAM/APB mass ratio (as shown in Fig. 5), in variation range of gel fraction. Gel fraction varied within the range between $65 \%$ to $70 \%$ with starch/(AAM+APB) mass ratio increasing from 6:6 to 6:18. By comparison, gel fraction varied within the range between $63 \%$ to $70 \%$ with absorbed dose increasing from $1 \mathrm{kGy}$ to $5 \mathrm{kGy}$, but gel fraction increased dramatically from $31 \%$ to $69 \%$ with AAM/APB mass ratio increasing from $0: 14$ to 8.4:5.6.

\section{Summary}

ST/AAM/APB hydrogels were synthesized in an aqueous medium using gamma irradiation as an initiator in the presence of cross-linker MBA. The molecular mass of the un-grafted copolymer of AAM and APB increased with the increase in absorbed dose from $3 \mathrm{kGy}$ to $9 \mathrm{kGy}$, and was markedly low at $1 \mathrm{kGy}$ of absorbed dose, and simultaneously the content of un-reacted monomers or their low molecular mass derivatives was high at $1 \mathrm{kGy}$. In addition, the increase of absorbed dose from $3 \mathrm{kGy}$ to $9 \mathrm{kGy}$ had little effect on thermal-decomposition temperature of dry ST/AAM/APB hydrogels.

Gel fraction varied in a limited range of $63 \%$ to $70 \%$ either with absorbed dose increasing from $1 \mathrm{kGy}$ to $5 \mathrm{kGy}$, or with starch/(AAM+APB) mass ratio varying from 6:6 to 6:18, while gel fraction 
increased from $31 \%$ to $76 \%$ with starch/binary monomers mass ratio increasing from $0: 14$ to 11.2:2.8. On the other hand, $S_{e}$ decreased with absorbed dose increasing from $1 \mathrm{kGy}$ to $6 \mathrm{kGy}$ or starch/(AAM+APB) mass ratio changing from 6:3 to 6:14, while cationic degree had the opposite trend with $S_{e}$.

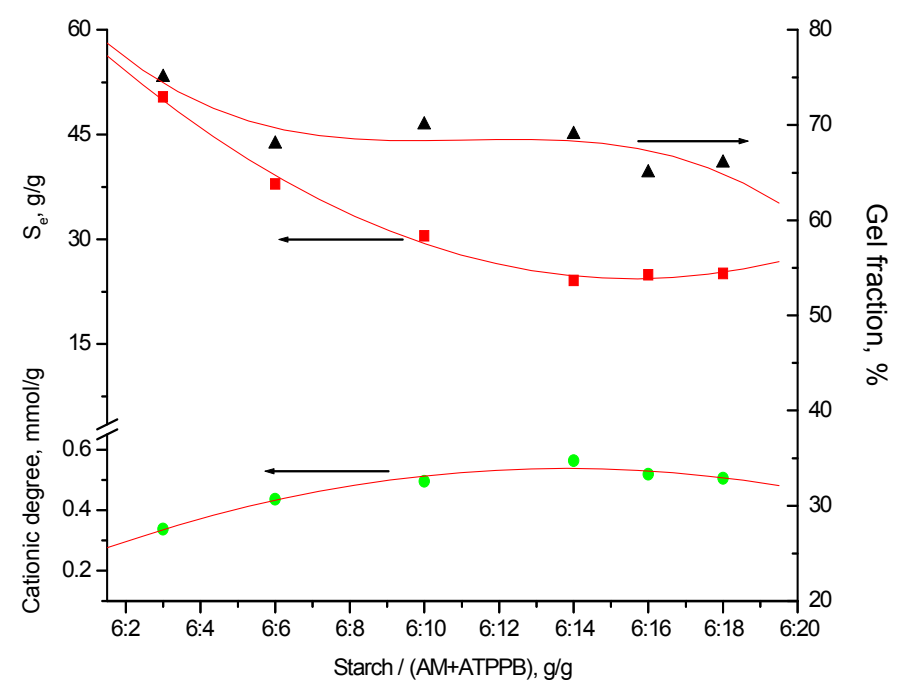

Fig. 6. Effect of starch/(AAM+APB) mass ratio on $S_{e}$, cationic degree and gel fraction of ST/AAM/APB hydrogels

\section{Acknowledgments}

The above research work was supported by the Natural Science Foundation of China (21404032), the Science and Technology Talents Team Construction Projects of Zhengzhou City (131PCXTD615), the Key Scientific and Technological Project of Henan Province (122102210219), the Development of Science and Technology Plan Projects of Zhengzhou City (20140771) and the Doctor Foundation of Henan University of Technology (2012BS029), China.

\section{References}

[1] V. Haack, T. Heinze, G. Oelmeyer and W.M. Kulicke: Macromol. Mater. Eng. Vol. 287 (2002), p. 495

[2] A. Kanazawa, T. Ikeda and T. Endo: J. Polym. Sci., Part A: Polym. Chem. Vol. 31(1993), p. 335

[3] W. Xie, R. Xie, W. Pan, D. Hunter, B. Koene, L. Tan and R. Vaia:Chem. Mater. Vol. 14(2002), p. 4837

[4] K. Neelam, S. Vijay and S. Lalit:Int. Res. J. Pharm. Vol. 3 (2012), p. 25

[5] J. Bao, Z. Ao and J-L. Jane: Starch/Stärke Vol. 57(2005) , p.480

[6] R. Bhat and A.A. Karim:Compr. Rev. Food Sci. F. Vol. 8(2009), p.44

[7] M. Eid:J. Inorg. Organometallic Polym. Vol. 21(2011), p. 297

[8] G.F. Fanta, R.C. Burr, W.M. Doane and C.R. Russell:J. Appl. Polym. Sci. Vol.18(1974) , p. 2205

[9] S. Kiatkamjornwong, W.Chomsaksakul and M. Sonsuk:Radiat. Phys. Chem. Vol. 59(2000), p. 413

[10] F. Parvin, M.A.Khan, A.H.M. Sadmat, M.A.H. Khan, J.M.M.Islam, M. Ahmed and M.A. Gafur: J. Polym. Environ. Vol.19(2011), p.1013

[11] A. Pourjavadi, R. Soleyman, Gh.R. Bardajee and F. Seidi:Trans. C: Chem. Chem. Eng. Vol.17(2010), p.15

[12] S. Mishra, R. Bajpai, R. Katare and A.K. Bajpai:Express Polym. Lett. Vol.1 (2007), p.407 
[13] F. Yoshii, L. Zhao, R.A. Wach, N. Nagasawa, H. Mitomo and T. Kume:Nucl. Instrum. Methods Phys. Res., Sect. B Vol.208(2003), p. 320

[14] S. Kiatkamjornwong, K. Mongkolsawat and M. Sonsuk:Polym. Vol.43 (2002), p. 3915

[15] R.M.A.E. Sadmany and Y.H. Foda:Starch/Stärke Vol. 28(1976), p.208

[16] M. Zhai, F. Yoshii, T. Kume and K. Hashim:Carbohydr. Polym. Vol. 50 (2002), p. 295

[17] D. Wu, Q. Shu, Z. Wang and Y. Xia: Radiat. Physi. Chem. Vol. 65(2002), p. 79

[18] X. Lv, W. Song, Y. Ti, L. Qu, Z. Zhao and H. Zheng:Carbohydr. Polym. Vol. 92 (2013), p. 388

[19] J. Block and O.S. Waters:Talanta Vol.14 (1967), p.1130

[20] S.L. Caër:Water Vol. 3(2011), p. 235

[21] T. Cay and R. Inam:J. Appl. Polym. Sci. Vol. 91(2004), p. 2168

[22] G.R. Bardajee, A. Pourjavadi, R. Soleyman and N. Sheikh: J. Iran. Chem. Soc. Vol. 7(2010), p. 652

[23] F. Henry, L.C. Costa and C. Aymes-Chodur:Radiat. Phys. Chem. Vol. 79 (2010), p. 75

[24] N.E. Jackson, J.C. Corey, L.R. Frederick and J.C. Picken:oil Sci. Soc. Am. J. Vol. 31(1967), p. 491

[25] N.M. Adzahan, D.M. Hashim, K. Muhammad and R.A. Rahman:Int. Food Res. J. Vol.16 (2009), p. 415

[26] E. Karadag, D. Saraydin, N. Sahiner and O. Guven:Pure Appl. Chem. A Vol.38 (2001), p.1105

[27] J. Rosiak, K. Burczak, T. Czolozynska and W. Pekala:Radiat. Phys. Chem. Vol. 22(1983), p. 917

[28] W. Song, Z. Guo, L. Zhang, H. Zheng and Z. Zhao:Radiat. Phys. Chem. Vol. 91(2013), p. 114

[29] F. Ganji, S. Vasheghani-Farahani and E. Vasheghani-Farahani:Iran. Polym. J. Vol. 19 (2010), p. 375

[30] K. Pal, A.K. Banthia and D.K. Majumdar: Des. Monomers Polym. Vol.12(2009), p. 197 